\title{
DESIGN AND IMPLEMENTATION OF WATER QUALITY CHECKING SYSTEM USING ARDUINO IN IOT
}

\author{
R.Rupa Srivallika Devi ${ }^{1}$ \\ UG Student, Kallam Haranadhareddy Institute of Technology, Guntur. \\ Dr.K.V. SubbaReddy ${ }^{2}$ \\ Professor, Kallam Haranadhareddy Institute of Technology, Guntur. \\ Mr.K. Kranthi Kumar ${ }^{3}$ \\ Assistant Professor, Kallam Haranadhareddy Institute of Technology, Guntur. \\ N.Harika ${ }^{4}$ \\ UG Student, Kallam Haranadhareddy Institute of Technology, Guntur. \\ P.Naga Anjali ${ }^{5}$ \\ UG Student, Kallam Haranadhareddy Institute of Technology, Guntur. \\ B.Prakasa Lakshmi ${ }^{6}$ \\ UG Student, Kallam Haranadhareddy Institute of Technology, Guntur.
}

Article DOI: $\underline{\text { https://doi.org/10.36713/epra3541 }}$

\begin{abstract}
Water pollution is one amongst the most important fears for the inexperienced economic process. because of the fast development and urbanization, the standard of water is obtaining degrade year by year, and it ends up in waterborne diseases and additionally effects turquoise culture. In India, sixty fifth of the drink comes from underground sources, therefore it's necessary to see the standard of the water. The planned system is presenting a style and development of low-price system for real time observance of the water quality victimization IOT, which may notice pollution remotely and take necessary actions. The system consists of many sensors are wont to measure physical and chemical parameters of the water, like temperature, $P H$, flow and cloudiness. Arduino IDE act as a base station and therefore the knowledge from sensing element nodes are send to that. furthermore, GSM is connected to Arduino that compares sensing element prices to threshold prices and sends a text conscious of the agent if the obtained value is on top of or below the brink value.
\end{abstract}

KEYWORDS: Arduino, IoT, Water Samples, GSM, Sensors.

\section{I.INTRODUCTION}

Currently beverage is extremely prized for all the humans. Here is no life while not water. people in general rely heavily on water for survival. They, as an example, don't eat food for many days, however cannot survive while not beverage. Today, 1.1 billion folks lack access to associate improved water resource and over 3 million folks, largely kids, die annually from water-related diseases (UNICEF, 2015).[1] Internet of Things is a system of interconnected devices enabled to work and exchange data without human involvement.[2] with IoT many new areas innovations are created one of thing is Industrial Internet of Things IIOT it is with industrial 


\section{EPRA International Journal of Research and Development (IJRD)}

applications used in various business fields[3]. With IoT smart things are possible.[4] Building any application with IoT is a complex task because it combines many heterogeneous technologies.[5].Big network is created due to IoT [6].Blockchain technology is also used with Iot.[7] Various computing technologies are used very efficiently in IoT to provide computing capabilities.[8]Security is one of the big challenge in IIOT[9] The impact of IoT is everywhere[10].it's utterly clear that water quality has tremendous effects on human health each within the short term and within the semi-permanent. insanitary water, particularly contaminated and unboiled water containing variety of viruses and harmful germs is prejudicial to human health. Drinking contaminated water, in medical term, could cause water-related diseases as well as looseness of the bowels, microorganism infectious disease, cholera, typhoid fever and plenty of different contagious diseases. Cholera, watery malady and one amongst the Cambodia's prime killers will kill folks in days, or perhaps hours if they're not treated in a very timely manner. there have been 128 watery malady deaths between middle November in 2009 and middle Feb in2010 give thanks to not victimization clean water (Seiff \& Chhorn, Feb 2010). River, lake and $\mathrm{H} 2 \mathrm{O}$ that consists of harmful substances cause folks to own looseness of the bowels and stomach-ache. This continually happens within the area unit or within the areas wherever poor folks haven't any access to safe beverage and are oblivious of the drawbacks of unsafe water. So, it's too vital to seek out the answer for water observation $\&$ system. IoT may be an answer. In recent days, development in computing and physical science technologies has triggered net of Things technology. net of Things is delineated because the network of physical science devices communication among them by the assistance of a controller. The IoT may be an assortment of devices that employment along so as to serve human tasks in associate economical manner. It combines machine power to send knowledge concerning the environments. These devices are in sort of sensors, appliances, embedded systems, and knowledge analysis microchips. This paper presents an occasional value water observation system, that may be an answer for the water wastage and water quality. Microcontrollers and sensors area unit used for that system. murkiness device is employed for measurement the cloudiness of water. the opposite parameters like $\mathrm{pH}$ scale, conduction, and Temperature of the water is calculated victimization totally different corresponding sensors. All the measured parameters area unit compared with the brink worth that defines the purity. Once the parameters area unit measured, they're sent to authority within the sort of alert messages. GSM Module sends the alert messages to mobile.

\section{II.LITERATURE SURVEY}

A survey on existing system, Traditional methods of water quality involve the manual collection of water sample at different locations, followed by laboratory analytical techniques in order to check the water quality. Such approaches take longer time and no longer to be considered efficient. Although the current methodologies analysis the physical, chemical and biological agents, it has several drawbacks:

a) Poor spatiotemporal coverage

b) Itis labor intensive and high cost (labor, operation; and equipment)

c) The lack of real time water quality information to enable critical decisions for public health protection.

Therefore, there is a need for continuous online water quality monitoring.

\section{PROPOSED SYSTEM}

The objective of proposed system is to provide methods for Portable and Automatic Water Quality Monitoring and Notification System which saves time and to mainly reduce the human intervention. This notification will be updated to the authorized person when sensor will detect the quality of water changes. Here ARDUINO UNO is used as core controller and various sensors to monitor the water Quality. Different sensors are connected to Arduino to monitor the conditions of water. The Arduino will access the data from different sensors and then processes the data. The sensor data can be viewed on the LCD.

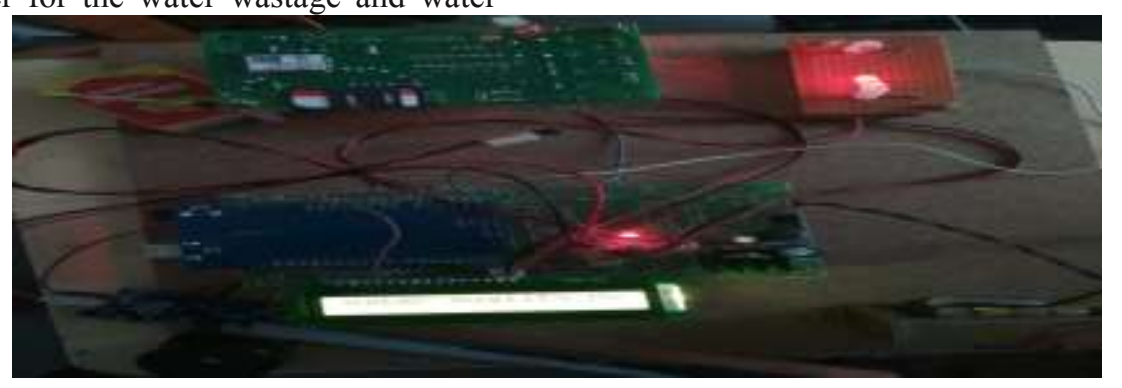




\section{IV.REQUIREMENTS}

\begin{tabular}{|c|c|c|}
\hline SNO & $\begin{array}{c}\text { SOFTWARE } \\
\text { REQUIREMENTS }\end{array}$ & HARDWARE REQUIREMENTS \\
\hline $\mathbf{1}$ & ARDUINO IDE & Arduino Uno \\
\hline $\mathbf{2}$ & - & Temperature sensor \\
\hline $\mathbf{3}$ & - & pH sensor \\
\hline $\mathbf{4}$ & - & Turbidity sensors \\
\hline $\mathbf{5}$ & - & Conductivity Sensor \\
\hline $\mathbf{6}$ & - & Power supply \\
\hline
\end{tabular}

\section{V.ARCHITECTURE\&RELATED WORK}

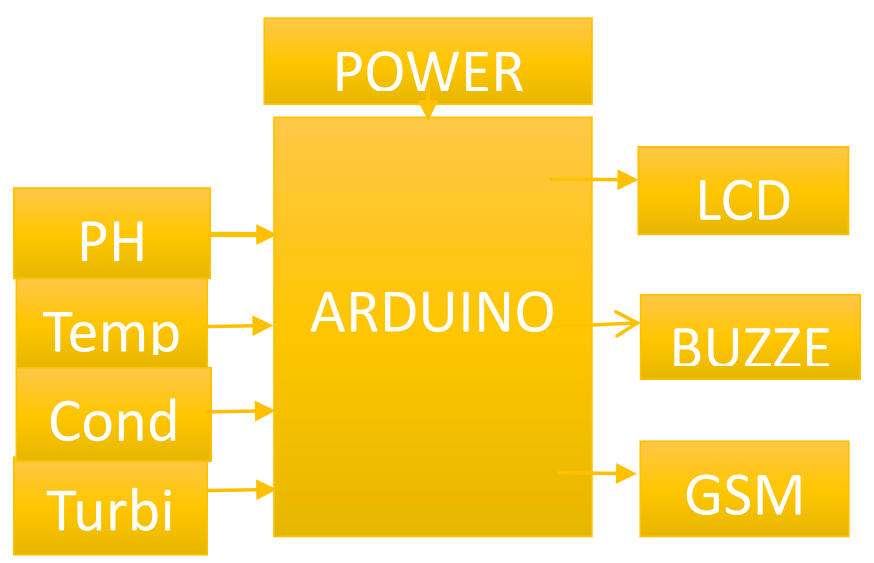

The system architecture of the proposed system is mainly controlled by microcontroller (ATmega328P).The power supply of Arduino Uno board is $9 \mathrm{~V}$, which is directly connected to Arduino Uno with step-down transformer. User collects the water samples. Sensors like $\mathrm{pH}$, temperature, turbidity, conductivity are used to check the purity level of water. Arduino accepts and processes the data collected from the sensors, displays the purity level of water on LCD and further communication is done by the GSM module, which sends an SMS with the water quality parameters onto the smart phone/PC.
As mentioned above architecture has following the list of components

1. $\mathrm{pH}$ Sensor

2. Conductivity sensor

3. Turbidity Sensor

4. GSM Module

5. Arduino

6. LCD Screen

7. Buzzer

8. Power Supply 


\section{VI.ALGORITHM \&FLOW DIAGRAM:}

Step 1: Start

Step 2: Establish the Connection between Controller and Network

Step 3: Display Initial Values of all the Sensors on LCD

Step 4: Check pH Value

If $\mathrm{pH}$ Value $>=7.30$

Water is High Alkaline

Else If $\mathrm{pH}$ Value $<6.89$

Water is Acidic

Else If $\mathrm{pH}$ Value $>=6.90 \& \& \mathrm{pH}$

Value $<7.29$

Water is safe

Step 5: Check Turbidity Value

If Turbidity>Threshold

Impure Water

If Turbidity<Threshold

pure Water

Step 6: Check Temperature

If Temp $>=45$

Buzzer ON(as an alert message)

Step 7: Check Conductivity

If Conductivity b/w 50 to 500

Pure water

Step 8: if Sensor Values are Changed 


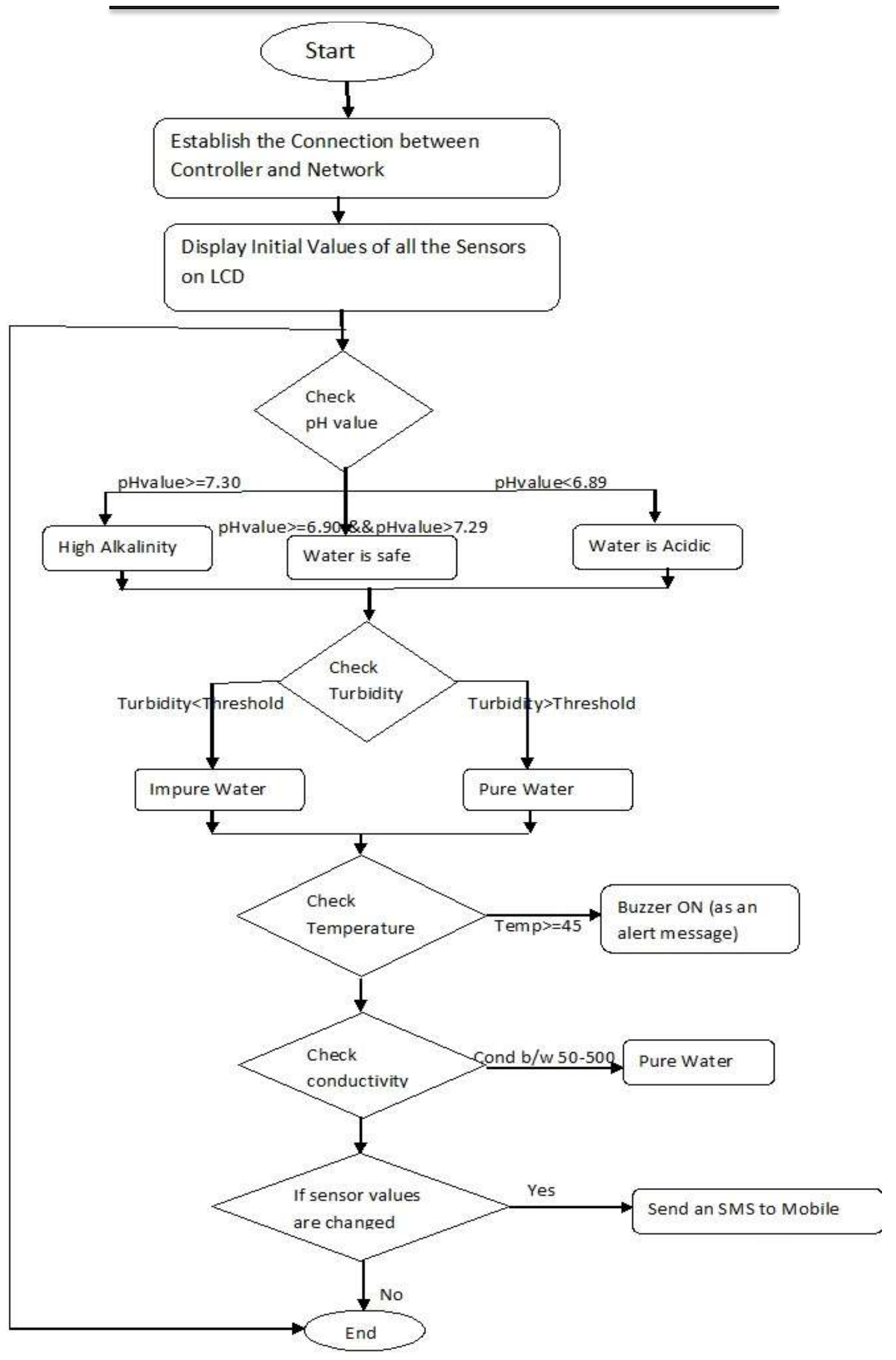




\section{EPRA International Journal of Research and Development (IJRD)}

\section{VII.IMPLEMENTATION}

This system makes use of four sensors $(\mathrm{pH}$, conductivity, turbidity, and temperature), processing module Arduino, and two data transmission modules Arduino and GSM. The four sensors capture the data in the form of analog signals. The ADC converts these signals into the digital format. These digital signals are sent to the Arduino via a GSM module. The microcontroller will process the digital information, analyse it, and further communication is done by the GSM module, which sends an SMS with the water quality parameters onto the smart phone/PC, which also displayed on the LCD of the Arduino. Arduino accepts and processes the data collected from the sensors. This is carried out with the help of coding. The code is written in Cprogramming and using the Arduino software to simulate the code. The entire code is dumped into the integrated circuit. Arduino UNO is a microcontroller board which has 14 digital input/output pins (of which 6 can be used as PWM outputs), 6 analog inputs. The LCD is connected to 2, 3, 4,5,7,6 digital pins in an Arduino. The sensors, Temperature sensor to $\mathrm{A} 2 \mathrm{pin}, \mathrm{pH}$ and conductivity to $\mathrm{A} 0$ pin, Turbidity to $\mathrm{A} 1$ pin and Buzzer is connected to analog pin 13. The $\mathrm{pH}$ sensor is a measure of how acidic or basic alkalinity of water? The $\mathrm{pH}$ scale is logarithmic and goes from 0 to 14 , where the range from 0 to 6 says that the water is acidic in nature and the range from 7 to 14 says it is basic in nature. The temperature sensor is used to measure temperature of water. If the temperature exceeds 45 then the Buzzer will on as an alert message. The turbidity sensor is used to measure the cloudiness of water. The conductivity sensor is used to measure the purity of water and the conductivity ranges from 100 to 1000 the water is fresh water.

\section{RESULTS}

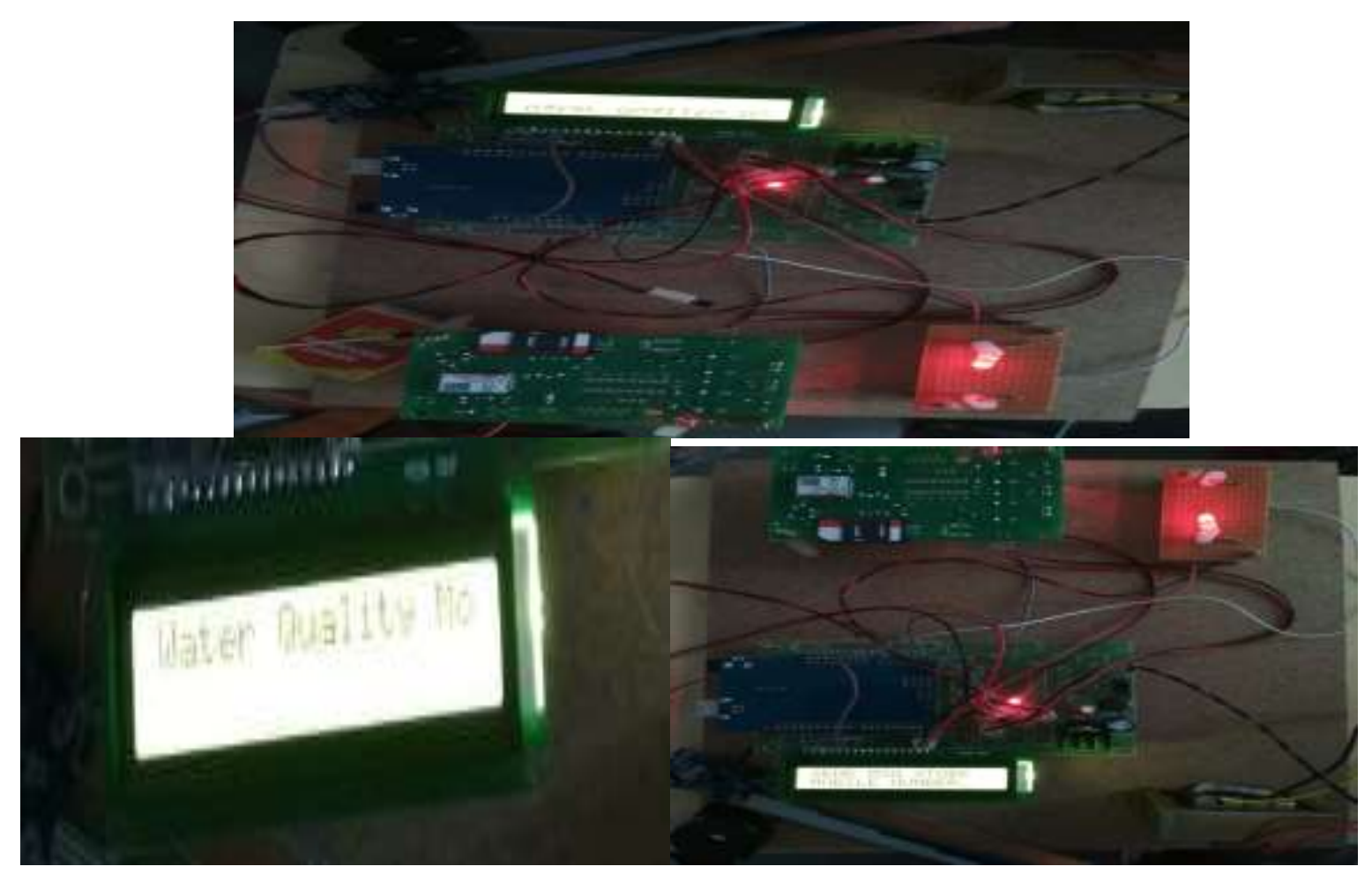



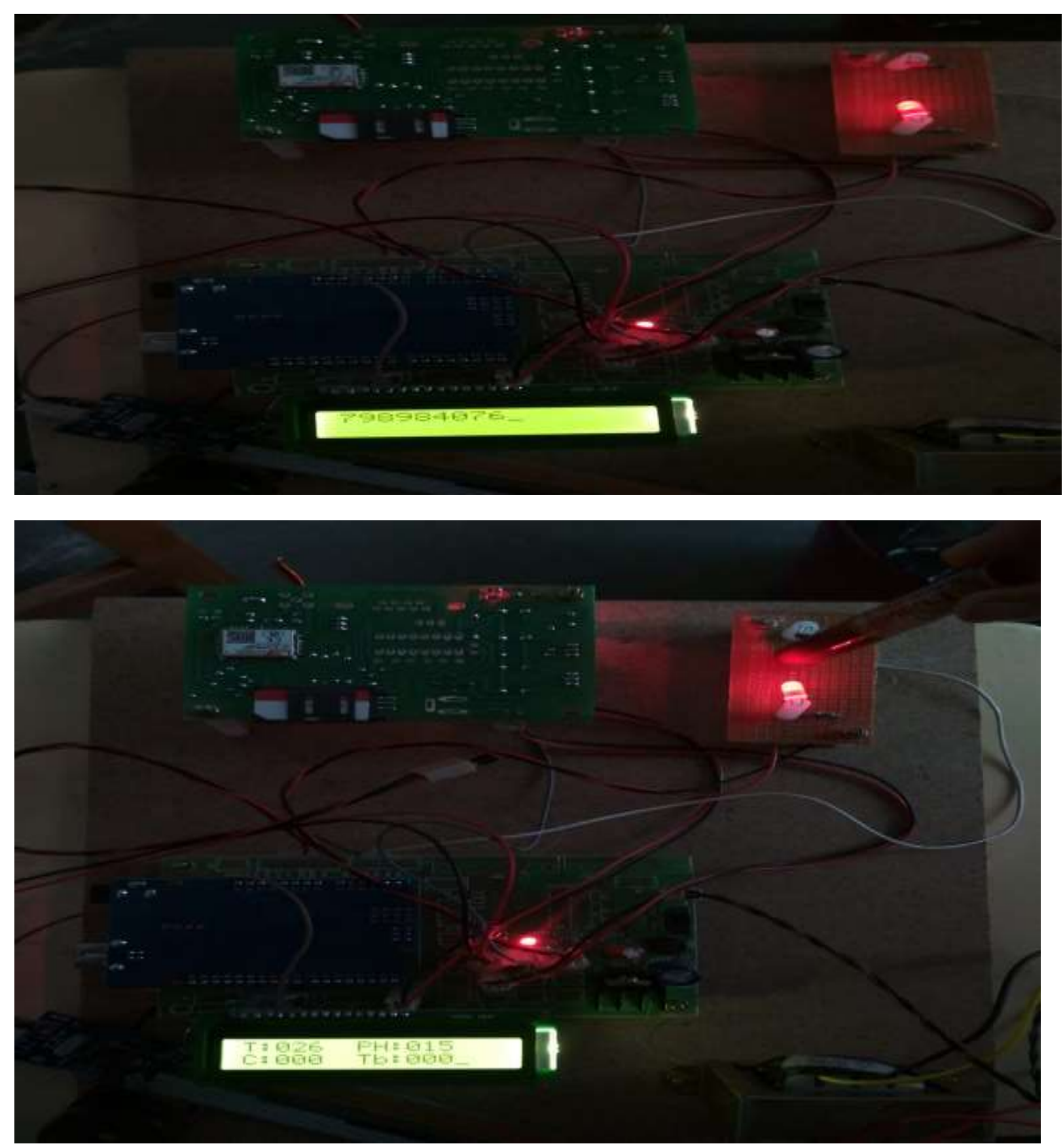


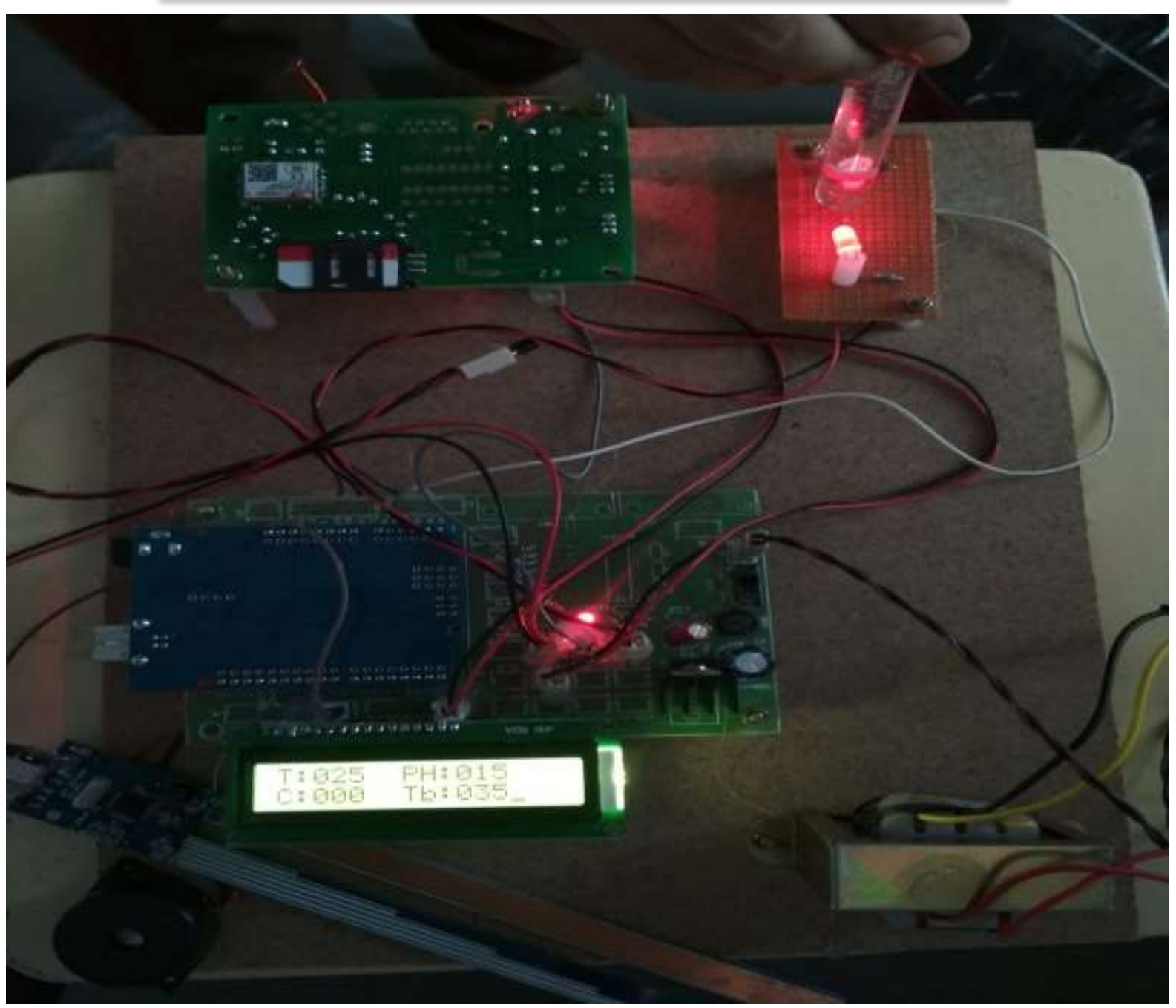


SJIF Impact Factor: 7.001| ISI I.F.Value:1.241| Journal DOI: 10.36713/epra2016

ISSN: 2455-7838(Online) EPRA International Journal of Research and Development (IJRD)

Volume: 5 | Issue: 5 | May 2020 - Peer Reviewed Journal
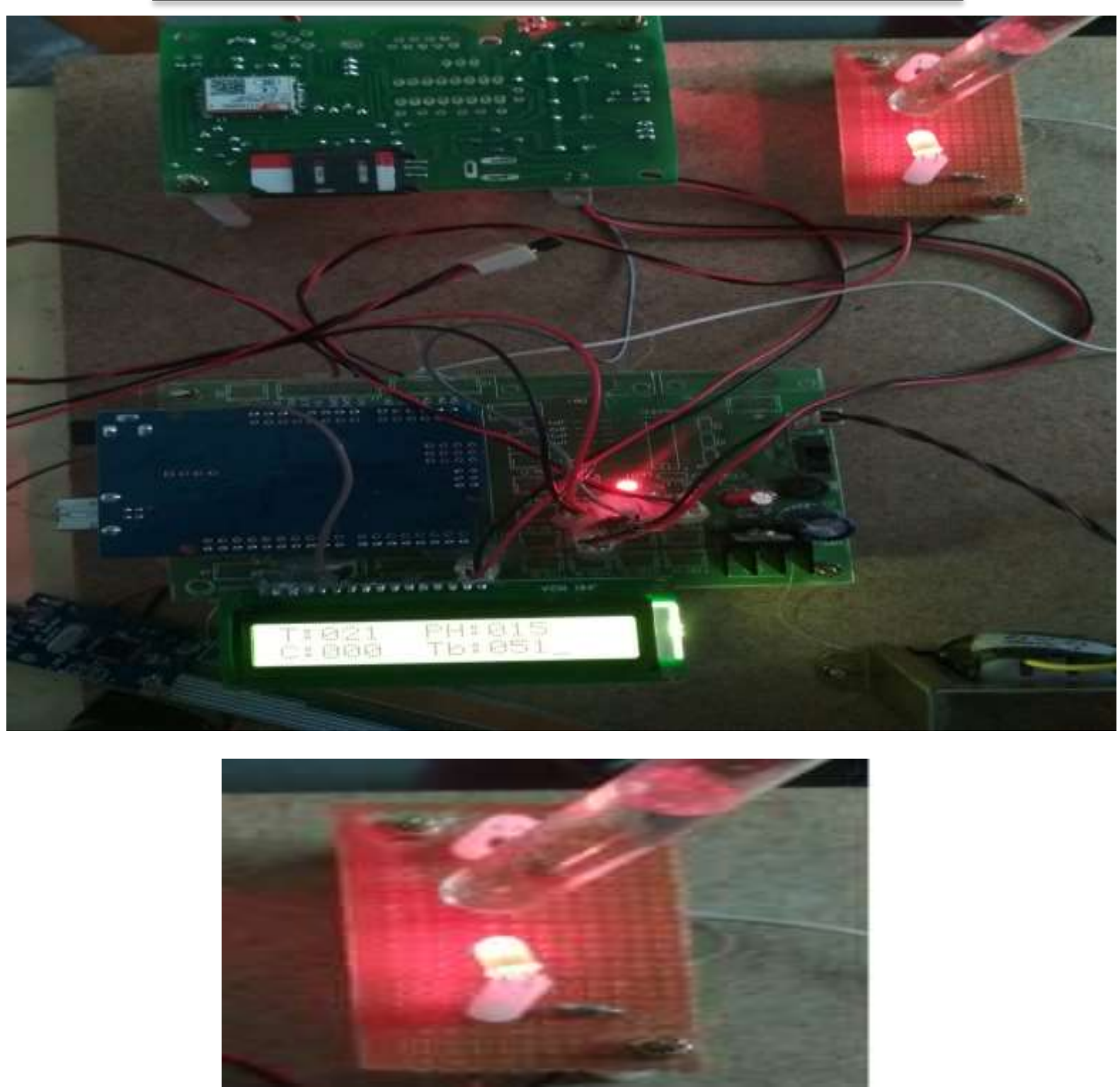

8897323045

India

Received

7989848076

Reg

Temp:00025 PH:00015 Cond:

00000 Turb:00025

\footnotetext{
(6) 2020 EPRA IJRD | JournalDOI: https://doi.org/10.36713/epra2016 |www.eprajournals.com |122 |
} 


\section{EPRA International Journal of Research and Development (IJRD)}

Volume: 5 | Issue: 5 | May 2020

- Peer Reviewed Journal

\begin{tabular}{|l|l|l|l|l|l|}
\hline Sno & Temperature & Turbidity & Conductivity & PH Value & Water \\
\hline 1 & 25 & 25 & 00 & 06 & $\begin{array}{l}\text { Pure } \\
\text { Water }\end{array}$ \\
\hline 2 & 028 & 35 & 00 & 16 & $\begin{array}{l}\text { Acid } \\
\text { Water }\end{array}$ \\
\hline 3 & 031 & 30 & 00 & 12 & $\begin{array}{l}\text { Salt } \\
\text { Water }\end{array}$ \\
\hline 4 & 035 & 51 & 00 & 20 & $\begin{array}{l}\text { Mud } \\
\text { Water }\end{array}$ \\
\hline
\end{tabular}

\section{Chart Title}

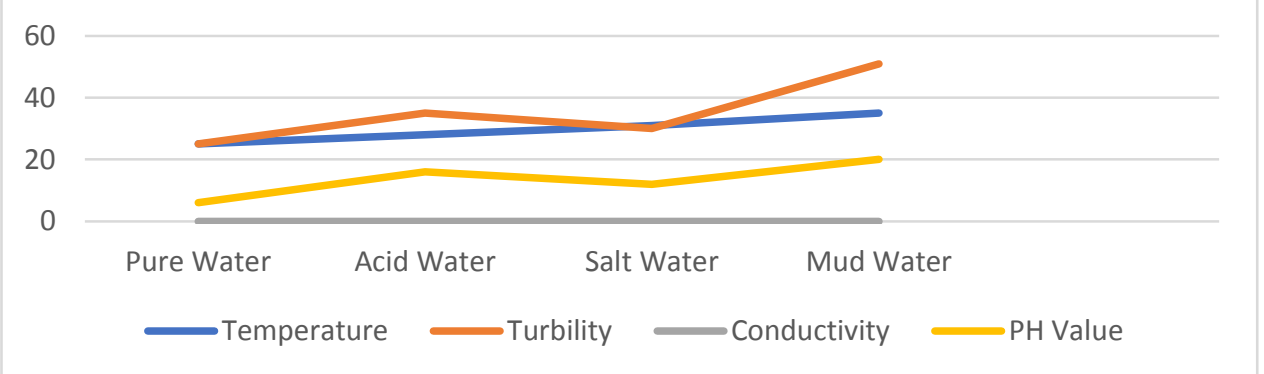

\section{VIII.CONCLUSION}

Monitoring of Turbidity, PH \& Temperature of Water makes use of water detection sensor with unique advantage and existing GSM network. The system can monitor water quality automatically, and it is low in cost and does not require people on duty. So the water quality testing is likely to be more economical, convenient and fast.The system has good flexibility. Only by replacing the corresponding sensors and changing the relevant software programs, this system can be used to monitor other water quality parameters.

\section{IX.FUTURE WORK}

In this paper we tested water quality with the help of arduino and few sensors in furure we may do a project with Rasberry Pi.

\section{REFERENCES}

1. https://www.unicef.org/publications/files/UNICE F_Annual_Report_2015_En.pdf.

2. https://en.wikipedia.org/wiki/Internet_of_things.

3. https://en.wikipedia.org/wiki/Industrial internet of things.

4. https://en.wikipedia.org/wiki/Building_automatio $\underline{n}$.

5. "Internet of Things for Smart Cities", Andrea Zanella; Nicola Bui; Angelo Castellani; Lorenzo Vangelista ; Michele Zorzi(Volume: 1, Issue: 1, Feb. 2014), DOI: 10.1109/JIOT.2014.2306328.

6. "A Vision of IoT: Applications, Challenges, and Opportunities With China Perspective”,Shanzhi
Chen; Hui Xu; Dake Liu; Bo Hu; Hucheng Wang- DOI: 10.1109/JIOT.2014.2337336

7. "Blockchain-Enabled Wireless Internet of Things: Performance Analysis and Optimal Communication Node Deployment", Yao Sun ; Lei Zhang; Gang Feng ; Bowen Yang; Bin Cao ; Muhammad Ali ImranDOI: $10.1109 /$ JIOT.2019.2905743.

8. "A Survey on Internet of Things: Architecture, Enabling Technologies, Security and Privacy, and Applications", Jie Lin; Wei Yu ; Nan Zhang ; Xinyu Yang ; Hanlin Zhang ; Wei ZhaoDOI: 10.1109/JIOT.2017.2683200.

9. " Machine Learning-Based Network Vulnerability Analysis of Industrial Internet of Things" Maede Zolanvari; Marcio A. Teixeira ; Lav Gupta ; Khaled M. Khan ; Raj Jain-DOI: 10.1109/JIOT.2019.2912022.

10. "A Survey on Security and Privacy Issues in Internet-of-Things, Yuchen Yang; Longfei $W u$; Guisheng Yin; Lijie Li ; Hongbin ZhaoDOI: 10.1109/JIOT.2017.2694844. 